\title{
Monitoring During Colonoscopy
}

\author{
Rosalinda S. Hulse \\ Jordan Hospital, Plymouth, MA
}

USA

\section{Introduction}

Many individuals are still hesitant to undergo colonoscopy despite numerous advertisements and campaigns about it. A few years back, a famous TV personality named Katie Kouric, had her colonoscopy broadcasted through live television because she wanted the public to see that there's nothing scary or frightening about the procedure. Her husband died of colon cancer at a young age. Had he had a colonoscopy (Fig. 1), his cancer would have been diagnosed and treated early which could have saved or prolonged his life.

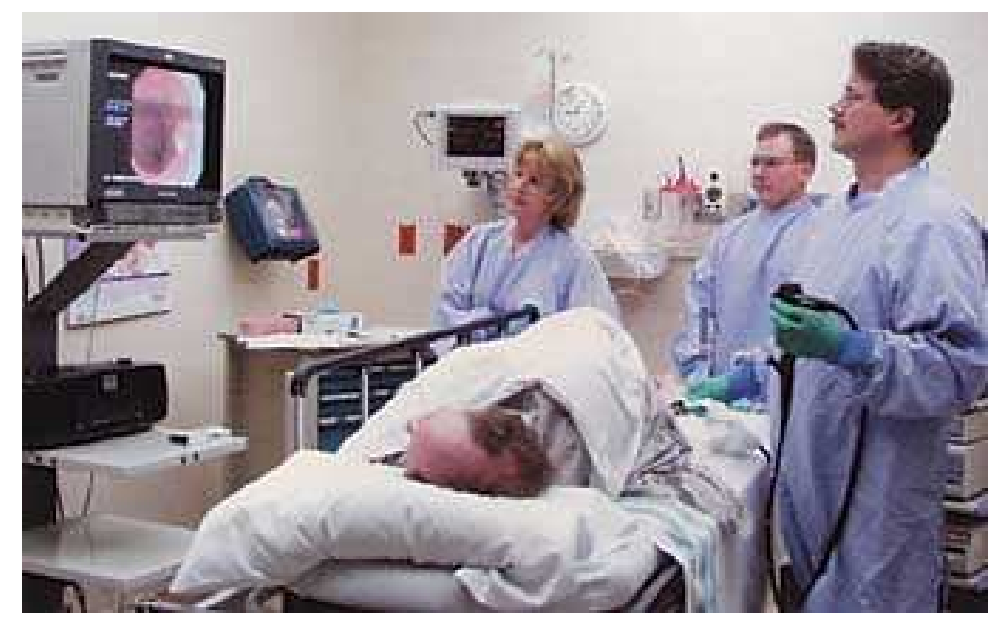

Fig. 1. Colonoscopy.

The test remains an uncomfortable, frightening, and embarrassing and anxiety producing situation, especially for people undergoing it for the first time, which can then lead to delays in screening and treatment. Though endoscopic procedures can be performed and tolerated without sedation, studies have shown that " $16 \%$ to $56 \%$ of such procedures are terminated because of pain". ${ }^{22}$ The goal of colonoscopy is to reach the cecum (the beginning of the large intestine). The scope is less likely to reach that destination, as it navigates the long and tortuous colon, without adequate sedation. Figure 2 shows the colon or large intestine and its location in the abdomen. 
Many countries around the world commonly perform colonoscopy without sedation. ${ }^{12}$ In Japan, though endoscopic procedures are routinely carried out without sedation, many Japanese are now choosing this to ease the discomfort. ${ }^{32}$ Only $2 \%-7 \%$ would prefer this option in the United States. ${ }^{29}$

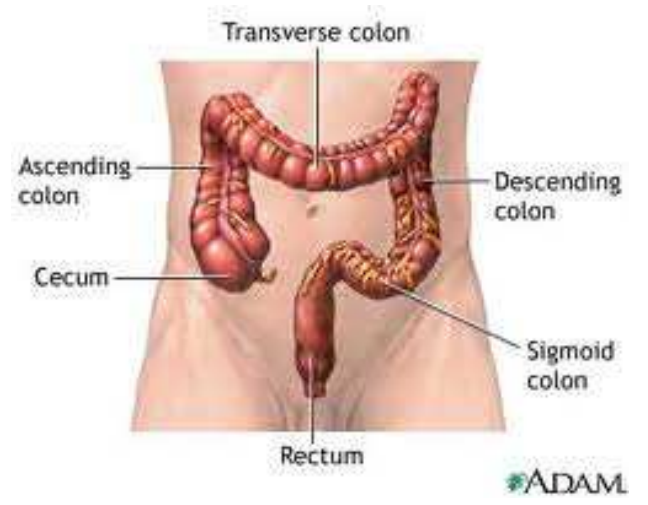

Fig. 2. The colon or large intestine

The challenge and goal of sedation in colonoscopy is to effectively facilitate the procedure while relieving anxiety, pain or discomfort, providing amnesia, and preserving cardiopulmonary function of the individual, with minimal cognitive impairment post procedure. This may delay the individual's discharge from the hospital. Sedation is now the standard of practice for endoscopic procedures in the U.S. and in many other countries. It is necessary to complete the procedure with ease and comfort. ${ }^{26,19}, 21,23,9,32,31,38$ Currently used medications are: benzodiazepines (e.g., midazolam, diazepam), opioids (e.g., meperidine, sublimaze), and propofol. Ketamine and inhaled anesthetics (e.g. nitrous oxide) are rarely used because of their side effects and uneasiness of administration. $.^{23}, 22$ These drugs are used alone or in combination with another drug. Comparison studies have been done to determine which combination of drugs are better in minimizing cognitive impairment post procedure, but none have been found to be better than the other. ${ }^{21}$ The ideal amount of sedation for a patient undergoing colonoscopy has also not been established despite the many different techniques, medications and combinations thereof attempted.

This chapter will discuss the different types of moderate sedation given, who will be administering it, and how individuals are monitored during the procedure. The goal is to inform the public of the different methods of making one comfortable during colonoscopy. Emphasis will be given to the fact that this procedure is short and safe, and usually does not require administration of heavy-duty anesthetics or sedatives. Monitoring is done frequently with particular attention to the airway, breathing (using pulse oximetry and capnography) and circulation i.e., heart rate and blood pressure. Knowledge of the availability of these medications will make the individual feel confident that he or she will be comfortable and cared for during his or her colonoscopy. 

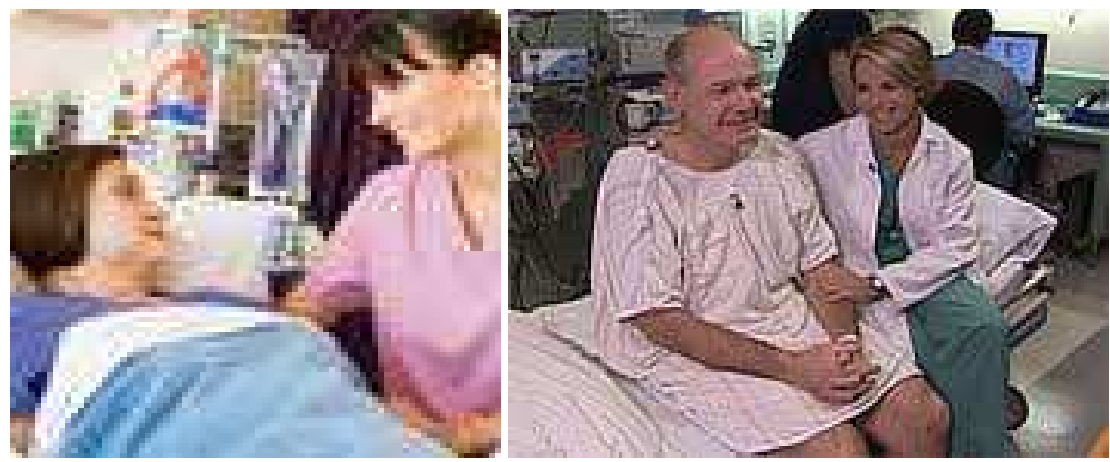

Fig. 3. Confidence and satisfaction in colonoscopic procedures

\section{Safety and efficacy of currently used sedation drugs for colonoscopy}

Sedation is defined as the calming of mental excitement or abatement of physiologic functions with the administration of a drug, ${ }^{31}$ i.e. a drug-induced depression of the individual's level of consciousness. ${ }^{4}$ As mentioned earlier, sedation is recommended in most endoscopic procedures to facilitate completion of the procedure, which in this case, would be colonoscopy.

Four levels characterize sedation: minimal or light (anxiolysis) sedation, moderate sedation (formerly known as conscious sedation), deep sedation, and general anesthesia. ${ }^{2}$ The most commonly used in colonoscopy is moderate sedation, where the patient continues to respond purposefully to verbal commands, with or without light touch stimulation. He is spontaneously breathing on his own and may be supported with minimal amounts of oxygen via a nasal cannula or sometimes a mask may be necessary. In deeply sedated states, patients may not be roused easily, and respond only after repeated or painful stimuli. They may also not have spontaneous respirations (breathing on their own) requiring assistance to maintain a patent airway. General anesthesia is normally reserved for surgical procedures wherein patients do not respond to any form of stimulation, are completely immobile and support of his or her cardiovascular functioning is required. ${ }^{4}$ Table 1 shows summary of the various levels of sedation and analgesia. Adapted from the American Society of Anesthesiologists Standards and Guidelines (2009). ${ }^{2}$

Moderate anesthesia care (MAC) and/or moderate level of sedation (also formerly known as conscious sedation) is usually employed during colonoscopy. It allows for better patient cooperation and a quicker or shorter recovery time. ${ }^{26}$ Individuals certified to administer the drugs and monitor the patient's response(s), such as a gastroenterologist, a registered nurse, a certified registered nurse anesthetist, or an anesthesiologist, can safely administer this. ${ }^{32}$ However, there are some differences between MAC and moderate sedation. During moderate sedation, a physician personally administers or supervises a nurse to administer the sedative and/or analgesic drug. These individuals are qualified and certified to administer the sedation drugs maintaining the level of sedation to a "moderate" or lesser degree. They continually monitor and assess the effects of these drugs and level of sedation the patient is in throughout the duration of the procedure, are competent to recognize changes especially when the individual goes into a deeper level than originally intended 
and, are able to manage the consequences and adjust additional doses of the medication to maintain the desired level of consciousness.

\begin{tabular}{|c|c|c|c|c|}
\hline & $\begin{array}{c}\text { Minimal or } \\
\text { Light } \\
\text { Sedation } \\
\text { (Anxiolysis) }\end{array}$ & $\begin{array}{l}\text { Moderate } \\
\text { Sedation or } \\
\text { Analgesia } \\
\text { (Conscious } \\
\text { Sedation) } \\
\end{array}$ & $\begin{array}{l}\text { Deep Sedation } \\
\text { or Analgesia }\end{array}$ & $\begin{array}{c}\text { General } \\
\text { Anesthesia }\end{array}$ \\
\hline Responsiveness & $\begin{array}{c}\text { Normal } \\
\text { response to } \\
\text { verbal stimuli }\end{array}$ & $\begin{array}{l}\text { Purposeful } \\
\text { response to } \\
\text { verbal or } \\
\text { tactile stimuli }\end{array}$ & $\begin{array}{l}\text { Purposeful } \\
\text { response } \\
\text { following } \\
\text { repeated or } \\
\text { painful stimuli }\end{array}$ & $\begin{array}{l}\text { Unarousable } \\
\text { even with } \\
\text { repeated or } \\
\text { painful stimuli }\end{array}$ \\
\hline Airway & Unaffected & $\begin{array}{c}\text { No } \\
\text { intervention } \\
\text { required }\end{array}$ & $\begin{array}{c}\text { Intervention } \\
\text { may be } \\
\text { required }\end{array}$ & $\begin{array}{l}\text { Intervention is } \\
\text { often required }\end{array}$ \\
\hline $\begin{array}{l}\text { Spontaneous } \\
\text { Ventilation }\end{array}$ & Unaffected & Adequate & $\begin{array}{l}\text { Maybe } \\
\text { inadequate or } \\
\text { compromised }\end{array}$ & $\begin{array}{c}\text { Frequently } \\
\text { inadequate and } \\
\text { is } \\
\text { compromised }\end{array}$ \\
\hline $\begin{array}{l}\text { Cardiovascular } \\
\text { Function }\end{array}$ & Unaffected & $\begin{array}{c}\text { Usually } \\
\text { maintained }\end{array}$ & $\begin{array}{c}\text { Usually } \\
\text { maintained }\end{array}$ & $\begin{array}{l}\text { Maybe } \\
\text { impaired }\end{array}$ \\
\hline
\end{tabular}

Table 1. Summary of the various levels of sedation and analgesia. Adapted from the American Society of Anesthesiologists, Standards and Guidelines, 2009. ${ }^{2}$

In moderate sedation, the provider assigned to observing and monitoring the patient as well as administering the sedation medications has other responsibilities and tasks that are interruptible and of short duration. The reverse is true for moderate anesthesia care or MAC, where the provider (usually an anesthesiologist or nurse anesthetist) is solely dedicated to the observation and monitoring of the patient and does not have any other procedure-related responsibilities. He must be prepared to convert to general anesthesia when the patient's cardiorespiratory status is compromised. It is an essential component of his initial assessment to evaluate the patient's actual or anticipated physiological problem that may compromise his cardiorespiratory status during the scheduled procedure. His ability to rescue a patient whose airway is compromised is a prerequisite to his ability to provide moderate anesthesia care. The administration of hypnotics, sedatives and analgesics, as well as other drugs commonly used for the induction and maintenance of general anesthesia is often, but not always, a part of monitored anesthesia care. ${ }^{4}$

Since sedation is a continuum, it is impossible to predict how an individual will respond to the drugs. Some patients may require only small amounts of sedation, but MAC is often indicated because even small doses of these medications could precipitate adverse physiologic responses that would require acute clinical interventions and resuscitation. If a patient's health status or condition, or medical/surgical history is likely to require sedation to a deeper level or even to a momentary period of general anesthesia, then MAC is the preferred method. Due to the strong possibility that a deep or deeper level of sedation may transition to general anesthesia, the skills and expertise of an anesthesia provider (e.g. 
anesthesiologist or certified registered nurse anesthetist, CRNA) are essential to manage the effects of general anesthesia as well as the patient's quick return to a lesser state of sedation. MAC also includes post-procedure responsibilities such as ensuring return to full consciousness, complete relief of pain, management of side effects or any adverse physiologic responses from the drugs administered during the procedure, as well as the diagnosis and treatment of some co-existing medical problems. ${ }^{2}$

Since individuals vary in their responses to the sedation medication, and may be in different levels of sedation as well, while undergoing the same procedure, or may require different levels to complete the procedure; it is imperative that clinicians administering the sedatives/analgesics and monitoring their effects have the necessary skills and knowledge in recognizing complications associated with sedation/analgesia, and be able to rescue or resuscitate the individual whose sedation status is deeper than originally intended. ${ }^{4},{ }^{37}$ They must have also undergone a course or class and be certified in cardiopulmonary resuscitation (CPR) as well as in Advanced Cardiac Life Support (ACLS). $.^{\circ}, 16,{ }^{37},{ }^{3}$ In patients with significantly sedation-related risk factors, i.e., severe obstructive pulmonary disease, sleep apnea, potentially difficult airway, congestive heart failure, and coronary artery disease, the presence of an anesthesiologist is highly recommended. It is also recommended for patients who may require a deeper level of sedation to achieve adequate procedure result, such as individuals who are on high doses of psychotropic medications, benzodiazepines, alcohol, and narcotics. ${ }^{4}, 22,3$

\begin{tabular}{|l|l|}
\hline Class & Description \\
\hline ASA I & A normal healthy patient \\
\hline ASA II & $\begin{array}{l}\text { Patient has mild systemic disease which does not interfere with } \\
\text { daily activities, such as high blood pressure that is under control }\end{array}$ \\
\hline ASA III & $\begin{array}{l}\text { Patient has a moderate or severe systemic disease that does not } \\
\text { inhibit or limit daily activities such as diabetes with some } \\
\text { systemic complications }\end{array}$ \\
\hline ASA IV & $\begin{array}{l}\text { Patient has a severe systemic disease that is a constant threat to } \\
\text { life such as end-stage renal or liver failure, or congestive heart } \\
\text { failure }\end{array}$ \\
\hline ASA V & $\begin{array}{l}\text { The patient is moribund and is not expected to survive within } 24 \\
\text { hours, with or without the procedure }\end{array}$ \\
\hline ASA VI & $\begin{array}{l}\text { The patient is declared brain-dead and his or her organs are being } \\
\text { removed for donation purposes. }\end{array}$ \\
\hline E & $\begin{array}{l}\text { In addition to indicating the ASA status, a patient undergoing an } \\
\text { emergency procedure is indicated by the suffix "E." }\end{array}$ \\
\hline
\end{tabular}

Table 2. Patient status classification according to the American Society of Anesthesiologists (ASA)

Many studies have been performed regarding administration of these drugs during colonoscopy and were found to provide safe and effective sedation during the procedure, especially when titrated in small incremental doses. Though safe and effective, these drugs 
do carry potential problems or concerns that include cardiopulmonary events, such as hypotension, airway obstruction, hypoxia/hypoxemia, aspiration, apnea, arrhythmia, vasovagal episodes, and though uncommon, serious morbidity and death can also occur. ${ }^{24}, 15,16$ A review of data from the American Society for Gastrointestinal Endoscopy's (ASGE) computer-based management system of 21,000 GI endoscopies in 1988 using Versed (Midazolam) and Valium (Diazepam) revealed the following: Overall complication rate was 13.5 events per 1000 procedures and serious cardiopulmonary events were 5.4 per 1000 . Death occurred in 0.3 per 1000.5 Another study evaluating the safety of the combination of meperidine (Demerol) with either midazolam (Versed) or diazepam (Valium) revealed no deaths.6 Results from two other studies showed a considerably lower incidence of cardiopulmonary complications using propofol as compared with the use of benzodiazepines during routine endoscopic procedure..$^{38,25,28}$ Because of these potential complications, endoscopy suites are equipped with the tools necessary to rescue the patient. These include: a suction machine, oxygen outlet or tank, a code cart with a defibrillator, a bag-valve mask, oral and nasal airways, a nasogastric tube, materials for respiratory intubation, and drugs required for cardiorespiratory resuscitation. ${ }^{20}$

\section{Economics of sedation in endoscopy}

In the past, gastroenterologists have routinely administered the sedating agents to their patients as part of the colonoscopy service. However, in recent years, many endoscopists are employing the services of an anesthesiologist or a certified registered nurse anesthetist (CRNA) to administer the sedation. The influencing factors being, the increased use of propofol during this procedure, effective marketing by anesthesiologists, and by a decrease in reimbursements by insurers. ${ }^{4},{ }^{35}$

The approach of individual countries towards administration of sedatives and analgesics during colonoscopy varies widely due to differences in health insurance reimbursements and budget restraints. ${ }^{41}{ }^{22}$ In the United States, Medicare reimbursements for use of an anesthesiologist during colonoscopy are not uniform across the nation. Some health insurers also question the separate billing of anesthesia service when generally; reimbursement fee for the colonoscopy includes administration of sedation under the supervision of the

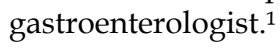

Ideally, an anesthesiologist is present in all cases of colonoscopy to optimize sedation and analgesia. However, his presence during this short procedure for individuals who are at average-risk for developing sedation-related complications is debatable and not costeffective. ${ }^{1}$ Normally, these patients are able to maintain their airway with minimal or no support so that the skills of an anesthesiologist is not necessary. Many studies have been done exploring the use of a registered nurse administering propofol and have found safety levels equivalent to those administered with benzodiazepines and narcotics. ${ }^{32,33}, 30,36$

\section{Colonoscopy without sedation}

In some instances, few selected patients opt to undergo their colonoscopy without sedation. In the US, a survey found that only $2 \%$ to $7 \%$ of individuals were willing to do their colonoscopies without sedation. ${ }^{29}$ Review of literature found no randomized control trials done to compare sedation versus no sedation during colonoscopy. Many argue that they want to watch the procedure and are fascinated by what's inside the human body. Some are 
unable to find an available designated driver and are unwilling to reschedule their appointment. Still some have stated that they have a lot of commitments and things to do that they cannot afford to skip a day to rest at home. In some rare instances, the individual went straight to work after his procedure. The type and level of monitoring should be tailored to each individual in these cases. Often, the individual is advised to bring a designated driver, in case he changes his mind and decides to receive sedation. Men, patients who are generally healthy and have no history of abdominal pain, individuals who are not anxious, and older patients may be better able to tolerate the colonoscopy without sedation. In situations like this, a smaller diameter endoscope (pediatric scope) is used and is better tolerated.

\section{Preprocedure assessment and monitoring}

A few weeks prior to the scheduled colonoscopy, the patient usually pays his endoscopist a visit to review his general state of health, medical and surgical histories, allergies, and regularly taken medications. Special instructions will be given to diabetics with regards to intake of their medications as well as diet. The appropriate bowel cleansing prep will be reviewed and instructions provided. The patient will also be informed that he will be receiving sedating medications to make the procedure more comfortable and tolerable. He is then advised to arrange for someone to drive him home because he will not be allowed to drive home, take the bus or taxi after the procedure due to the residual effects of the sedative; emphasizing the fact that these side effects do alter his reflexes and cognitive functioning. This usually wears off in about four to six hours; and, even after this time, the individual may still feel very tired and sleepy. Patients are discharged home and advised to take the day off and rest. They are normally allowed to eat light, non-spicy, and easily digestible foods to avoid nausea and vomiting which is often a side effect of sedatives and opioids.

The use of combination regimen as well as patient characteristics influence the safety and choice of sedative regimens for this procedure. Therefore, general data is collected from every patient, recorded in his medical record and reviewed by both the endoscopist and the personnel providing the sedating medication (s), shortly before the colonoscopy is performed. These include: name, age (determined by date-of-birth), sex, general condition of health (as outlined in the ASA classification, Table 2), daily medications taken, allergies, medical and surgical histories, adverse reactions to sedatives and anesthetics, and problems (if any) post procedure or surgery. The following historical events should also be obtained from the patient: any significant abnormalities of major organ or organ systems, snoring or sleep apnea (using CPAP or BiPap), time and type of last meal taken, use of illicit drugs, and alcohol and tobacco use. Regarding the "time and type of last meal taken," there are no absolute or ultimate guidelines regarding the stopping of oral intake prior to administration of sedatives. There are no supporting data showing a direct relationship between fasting time and risk of aspiration into the lungs. The ASA guidelines recommend that patients not have clear liquids two hours before the procedure and a light meal six hours before administration of any sedating medication. This would allow sufficient time for the stomach to adequately empty. ${ }^{4}$ According to the American College of Emergency Physicians, "recent food intake is not contraindicated for administering procedural sedation and analgesia, but should be considered in choosing the timing and target of sedation". ${ }^{8}$ 
Physical examination of the individual is obtained and recorded. These include, initial vital signs (temperature, heart rate, blood pressure, respiratory rate, and oxygen saturation), level of consciousness, examination of heart and lungs, and airway anatomy (using the Mallampati classification, Figure 4). The last one is important in situations where the individual may need resuscitative assistance such as: 1) individuals with a history of snoring, stridor, or sleep apnea and is using a CPAP or BiPAP machine, 2) neck abnormalities involving the neck and facial features (e.g. obese persons), short neck, limited neck extension, neck mass, cervical spine disease or trauma to the neck, tracheal deviation, advanced rheumatoid arthritis, decreased hyoid-mental distance $(<3 \mathrm{~cm}$ in adults), 3 ) abnormalities of the mouth such as protruding incisors, small opening ( $<3 \mathrm{~cm} \mathrm{n}$ adults), high arched palate, hypertrophy of the tonsils, nonvisible uvula (see class 4 of the Mallampati classification, Figure 4), edentulous, loose or capped teeth, macroglossia, 4) history of problems with sedation and anesthetics, 5) dysmorphic facial features such as trisomy and Pierre-Robin syndrome, and 6) jaw abnormalities such as trismus, significant malocclusion, micrognathia, and retrognathia. The ASA Task Force guideline states "that the presence of one or more sedation-related risk factors coupled with the potential for deep sedation will increase the likelihood of adverse sedation-related events." Consultation with someone trained in managing these complex situations, usually an anesthesiologist or a certified registered nurse anesthetist should be considered. ${ }^{4}$ The presence of an anesthesiologist is also highly recommended for the following situations:

- Significantly compromised individuals such as those with congestive heart failure, coronary artery disease, and severe obstructive pulmonary disease (COPD) on continuous oxygen therapy or using CPAP or BiPAP machines

- Individuals with difficult airways (such as those described above)

- Extremely obese individuals

- $\quad$ ASA status classification of Class III, IV, and V

- Increased risk of pulmonary aspiration

- The individual is pregnant

- If it appears that sedation (even with small doses) will make the patient unresponsive and airway will be compromised

- General anesthesia is necessary to complete the procedure while maintaining patient safety and comfort

- Unavailability of a trained practitioner to administer moderate sedation

- Anticipated intolerance of standard sedation drugs (e.g. alcohol or substance abuse)

- Adverse reactions to sedatives

- Inadequate response to moderate sedation

A Modified Aldrete score is also assigned (see post procedure monitoring). An intravenous access is established because sedation drugs are normally given intravenously. Fluids may or may not be routinely given depending on the institution's procedural policies and regulations. For female patients, it is necessary to mention the possibility of being pregnant or is pregnant. If in doubt, a pregnancy test may be performed. Lactating mothers should also mention if they are breastfeeding as most of the medication is excreted in breast milk.

Shortly before the procedure starts, the provider of the sedating medications will discuss with the patient the type of sedating medications to be given; its benefits, risks and complications, limitations and other alternatives. The endoscopist will also review the 
procedure with the patient. He will then sign the consent form allowing the endoscopist to perform the procedure and to be given sedating medications (if agreeing to sedation). The anticipated level of sedation should be congruent with the expected level of sedation by the individual as much as possible. The endoscopist will also review the colonoscopy procedure, the benefits, risks and complications to patients who are not receiving sedation. Preparation is the same as for sedation in the event that an emergency arises or the patient requests medication during the procedure.

\section{Mallampati classification}

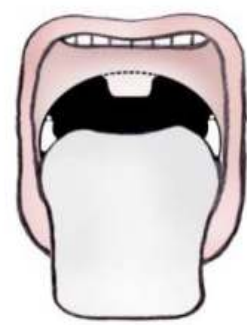

Class 1

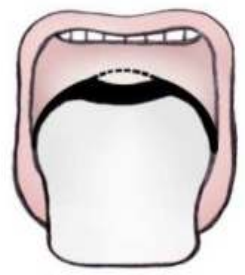

Class 3

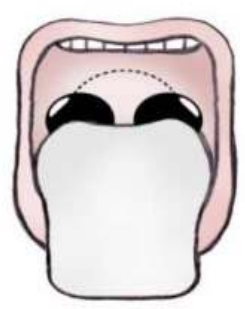

Class 2

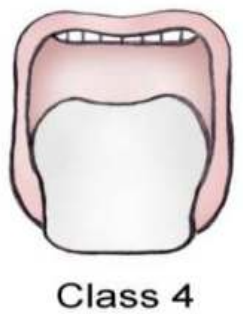

Fig. 4. Mallampati classification of airway management.

\section{Sedation and monitoring during colonoscopy}

According to the recommendations outlined by The Joint Commission and the Association of Anesthesiologists, hospital-based endoscopy suites consists of the following personnel: a physician endoscopist, an assisting nurse, and an additional nurse solely administering sedatives and monitoring the patient. ${ }^{14}$ However, with the advent and increased use of propofol, there has been a demand for the presence of an anesthesiologist or certified registered nurse anesthesiologist. This is partly due to the widespread perception that the drug carries major complication risks and statements emphasized by the information on the package insert of the drug itself, recommending that only personnel trained in the administration of general anesthesia administer this drug. The ASA guidelines also outlined numerous precautions regarding the administration of propofol thereby, increasing fears of non-anesthetists. It is also the perception that administration of benzodiazepines and opiates only induce moderate level of sedation and that propofol brings the patient into a deep level sedation..$^{\circ}$ Several studies though have proved that propofol can be safely administered by non-anesthesiologists. ${ }^{11}, 32,15,29$ 
Only $7.7 \%$ of gastroenterologists in the US administer propofol themselves without the assistance or presence of an anesthesiologist or nurse anesthetist (CRNA), and 68\% have expressed interest in incorporating it in their practice given proper training and adequately trained staff.9 The reason for the reluctancy among endoscopists to administer propofol themselves, are medico legal implications of the off-label use of propofol, the potential risks and complications, local institutional policy, and state regulatory restrictions. ${ }^{4}$ Hence, propofol is usually administered by an anesthesiologist (or by a certified registered nurse anesthetist [CRNA]) which is often not cost-effective in ambulatory gastrointestinal (GI) suites.$^{12}$ In some countries, like Switzerland, $34 \%$ of gastroenterologists polled administer propofol themselves. ${ }^{15}$

During the procedure, the patient is hooked up to a monitor that measures and displays the heart rate, blood pressure, and oxygen saturation (Figure 5) and in some cases, carbon dioxide levels (capnography). Some have also used transcutaneous carbon dioxide measurement or bispectral index monitoring (BIS). The latter is a quantitative assessment of cortical activity that has been used to monitor sedation and adjust sedation levels (Kissin, I., 2000). These are monitored by a licensed personnel (usually the person providing the sedation) every 3-5minutes during the procedure and with each incremental dose of the sedative. Monitoring may detect changes in the individual's blood pressure, heart rate, cardiac electrical activity, ventilatory, and neurologic status that might signal a clinically significant compromise of the patient's health status or that the patient has progressed to a deeper level of sedation than originally intended. Oxygen is usually given as an adjunct via a nasal cannula or mask as all of the sedation agents depress the respiratory system. The ASA guidelines recommend that patients receiving sedation medications receive continuous electrocardiogram (ECG) monitoring, especially if they have significant cardiovascular disease or arrhythmias. ${ }^{20}$ Parameters outlined in the Modified Aldrete scoring system, which includes the above mentioned items plus activity and consciousness are also monitored and recorded.

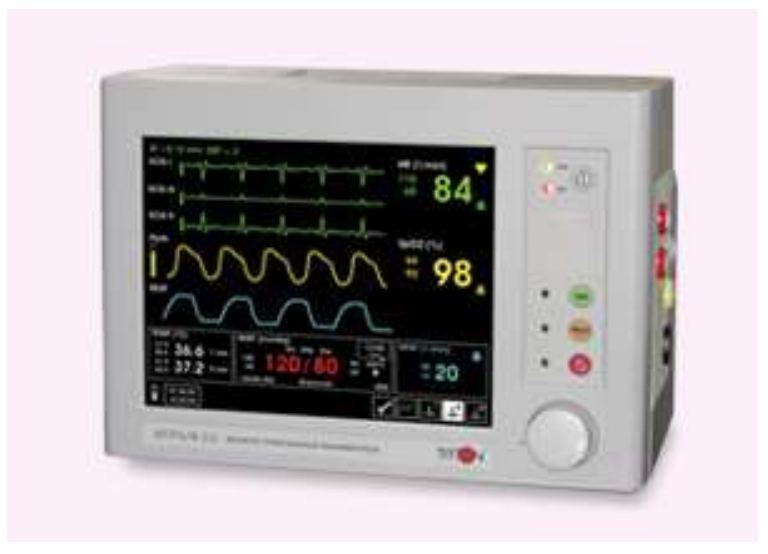

Fig. 5. Sample of monitoring equipment used

In most institutions, an intravenous access is started and IV fluids are given prior and during the procedure. This helps hydrate the patient, provide an avenue for the administration of sedating drugs, and as a rescue means should the patient become 
hypotensive (ASGE, 2008). Should the patient's condition get compromised or deteriorate at any given time during the procedure, the colonoscopy is halted and resuscitative measures are instituted. He may need to be transferred to the Critical Care Unit or the Emergency Department for further management.

\subsection{Post procedure monitoring}

Upon completion of the colonoscopy, the patient is kept in the room and monitored for a few more minutes until he is rousable and able to maintain his airway independently. Shortly thereafter, he is disconnected from all the monitoring equipment and brought to the recovery or discharge area to allow the effects of the sedatives to wear off. Here, the same parameters monitored during the procedure are monitored and recorded every 10-15 minutes for about half-an-hour to an hour, without the continuous cardiac monitoring (ECG) (unless warranted) and the carbon dioxide monitoring, until the patient is at or close to his or her baseline cognitive functioning level as possible, and is ready for discharge to home. Blood sugar levels of diabetics will also be checked and intervention given as necessary.

At this time, the endoscopist will come to discuss his findings during the procedure, any interventions done (i.e. biopsies taken), and discharge and follow-up instructions will be given. The patient's designated driver is encouraged to be present because he (the patient) may not remember what the endoscopist has said as a result of the amnesic properties of the sedatives, especially with benzodiazepines (not so with propofol), unless the patient requests otherwise. The patient is discharged when he or she has met discharge criteria as outlined by the Modified Aldrete or Aldrete and Kroulik scoring system (Tables 3 and 3.a) or whichever discharge scoring system the institution is using and has returned to his baseline (or close to it) level of cognitive and physiological functioning as possible.

Ideally, the recovery or discharge area should allow rapid recovery of the sedated individual, with minimal or without residual physiologic, cognitive or psychomotor impairments. Several discharge criteria have been formulated to facilitate and guide clinicians to objectively asses the clinical status of the sedated patient and be able to discharge him home. The most commonly used is the Modified Aldrete or Aldrete and Kroulik scoring systems (Table 3 and 3.a). ${ }^{39}$ The preferred method is the Modified Aldrete scoring system as most institutions do not use arterial pressure monitoring for endoscopy procedures, especially in an outpatient setting. This scoring is also used pre-, inta and post procedure. During the procedure, if the patient is maintained at the moderate sedation level, his score should be a 9 or a 10 or whatever his baseline score was at the start. Over sedation is defined by a score of less than 9 and corrective action should be initiated. All post sedation patients should have their vital signs back to within $10 \%$ of their baseline score or be admitted to the hospital for further evaluation especially if corrective/resuscitative actions have failed to improve his score or condition.

Post anesthesia discharge scoring system (PADSS) has been developed for post-anesthesia care units in Canada. This allows the health care providers to monitor the patient's readiness to be discharged home. The average length of time the sedated patient stays in the discharge or recovery area is half-an-hour to an-hour depending on the kind and amount of sedation drugs received during the procedure. Patients who receive propofol generally recover quicker and are discharged home in a much shorter time than those who receive benzodiazepines or in combination thereof. ${ }^{20}$ Prompt and safe discharge of the patients 
reduces the amount of time they stay in the discharge area and contributes to cost reduction and unit efficiency. ${ }^{7}$

\begin{tabular}{|c|c|c|}
\hline \multicolumn{3}{|c|}{ Modified Aldrete Scoring } \\
\hline Criteria & Ability & Score \\
\hline Activity & $\begin{array}{c}\text { Ability to move voluntarily or on command: } \\
\text { Four extremities } \\
\text { Two extremities } \\
\text { No movement }\end{array}$ & $\begin{array}{l}2 \\
1 \\
0\end{array}$ \\
\hline Respiration & $\begin{array}{c}\text { Able to cough and breathe deeply freely } \\
\text { Dyspnea, shallow or limited breathing } \\
\text { Apnea }\end{array}$ & $\begin{array}{l}2 \\
1 \\
0\end{array}$ \\
\hline Circulation & $\begin{array}{c}\text { Blood pressure within } 20 \mathrm{~mm} \mathrm{Hg} \text { of pre-sedation level } \\
\text { Blood pressure within } 20-50 \mathrm{~mm} \mathrm{Hg} \text { of pre-sedation level } \\
\text { Blood pressure }+50 \mathrm{~mm} \mathrm{Hg} \text { of pre-sedation level }\end{array}$ & $\begin{array}{l}2 \\
1 \\
0\end{array}$ \\
\hline Consciousness & $\begin{array}{l}\text { Fully awake } \\
\text { Arousable on calling } \\
\text { Not responding }\end{array}$ & $\begin{array}{l}2 \\
1 \\
0\end{array}$ \\
\hline O2 Saturation & $\begin{array}{l}\text { Able to maintain O2 saturation }>92 \% \text { on room air } \\
\text { Needs O2 to maintain O2 saturation }>90 \% \\
\text { O2 saturation is }<90 \% \text { even with O2 supplementation }\end{array}$ & $\begin{array}{l}2 \\
1 \\
0\end{array}$ \\
\hline
\end{tabular}

Table 3. Modified Aldrete Scoring System

\begin{tabular}{|c|c|c|}
\hline \multirow{2}{*}{ Assessment Item } & Condition & Grade \\
\hline & Moves 4 extremities & 2 \\
\hline \multirow[t]{3}{*}{ Muscle Activity } & Moves 2 extremities & 1 \\
\hline & Moves 0 extremities & 0 \\
\hline & Deep, Cough & 2 \\
\hline \multirow[t]{3}{*}{ Breathing } & Limited, Dyspnea & 1 \\
\hline & Apnea & 0 \\
\hline & Fully awake & 2 \\
\hline \multirow[t]{3}{*}{ Consciousness } & Awakens when called & 1 \\
\hline & Does not respond to call & 0 \\
\hline & + of $20 \%$ of pre-anesthesia level & 2 \\
\hline \multirow[t]{4}{*}{ Circulation $(\mathrm{AP})^{*}$} & $+20 \%$ to $49 \%$ of pre-anesthesia & \\
\hline & level & 1 \\
\hline & $+50 \%$ of pre-anesthesia level & 0 \\
\hline & Maintains SpO2 $>92 \%$ in ambient air & 2 \\
\hline \multirow[t]{2}{*}{$\mathrm{SpO} 2^{* *}$} & Maintains SpO2 > 90\% with O2 & 1 \\
\hline & Maintains SpO2 $<90 \%$ with O2 & 0 \\
\hline
\end{tabular}

${ }^{*} \mathrm{AP}=$ arterial pressure

** $=$ peripheral oxygen saturation

Table 3a. Aldrete and Kroulik Index 


\section{Commonly used sedation agents}

Colonoscopy procedures are usually done under moderate level of sedation or moderate anesthesia care (MAC). To achieve this, general practice guidelines call for the careful titration of the chosen sedative using incremental doses. The most commonly used agents are benzodiazepines, alone or in combination with an analgesic, and propofol, alone or also in combination with another agent. ${ }^{21},{ }^{2} 6,{ }^{22}$ The choice of sedating agent is largely dependent on the provider based on what he thinks and feels is the best in maximizing patient comfort at the same time, minimizing risks and complications. A US survey noted that over $85 \%$ of endoscopists use or prefer to use midazolam over diazepam. Only $10 \%$ have indicated preference for using diazepam.9

\subsection{Benzodiazepines}

The two most commonly used benzodiazepines are midazolam (Versed) and diazepam (Valium). Midazolam (Versed) is also classified as an anesthetic adjunct and as a short or intermediate acting hypnotic. It depresses subcortical levels in the Central Nervous System, may potentiate $\gamma$-aminobutyric acid (GABA), and may act on the limbic system and reticular formation. It is used for preoperative sedation, anxiety, intubation procedures, induction of general anesthesia, and for diagnostic endoscopic procedures. It can also be used for refractory status epilepticus. For moderate sedation or conscious

sedation during endoscopic procedures such as colonoscopy, midazolam can be used alone or in combination with a narcotic (e.g. an analgesic like meperidine or fentanyl). It is administered immediately prior to the procedure and supplemented by small incremental doses throughout until the desired effect is achieved to complete the procedure. ${ }^{21}$

Usual dosing for a healthy adult below 60 years of age range from $1 \mathrm{mg}$ to $2.5 \mathrm{mg}$ titrated slowly (within 2 minutes). Allow a 2-3 minute interval or more before administering any additional doses, and after each incremental dose to fully evaluate the desired sedative effect. A total dose greater than $5 \mathrm{mg}$ is usually not necessary and patients given an additional narcotic may only require $30 \%$ less of this drug, because of the cumulative CNS depressant effect (Product Info midazolam hcl injection, 2005). Patients 60 years and older, chronically ill, debilitated or with renal or hepatic insufficiency will require less, $1 \mathrm{mg}$ to $1.5 \mathrm{mg}$ titrated slowly intravenously (maximum infusion rate is $0.75 \mathrm{mg} / \mathrm{min}$ ). Again, allow 2 or more minutes before each additional dose to evaluate the desired sedative effect. A total dose of greater than $3.5 \mathrm{mg}$ is not necessary and individuals will normally require $50 \%$ less than what a normal healthy adult would receive especially if a narcotic were also added. An elderly patient should not receive a dose of more than $1.5 \mathrm{mg}$. The peak effect of the drug may take longer and the danger of apnea or hypoventilation is greater. Metabolites of midazolam can accumulate in patients with renal and hepatic failure and may prolong the sedative effect. Administration of midazolam is contraindicated in patients with hypersensitivity to any component of the drug, hypersensitivity to midazolam, acute narrow-angle glaucoma, untreated open-angle glaucoma, pregnancy, and status asthmaticus. $^{32}$

Midazolam is $97 \%$ protein bound; has a half-life of 1.8-6.4 hours; metabolized in the liver; excreted in the urine; and crosses the placenta and blood-brain barriers. Given intravenously, it has an onset of 1-5min, for a duration of 1-3 hours. Side effects of the drug include: headache, anxiety, insomnia, retrograde amnesia, euphoria, confusion, agitation, paresthesia, slurred speech, agitation, chills, arrhythmias, nausea, vomiting, hiccups, 
increased salivation, urticaria, swelling and/or itchiness at injection site, and coughing. Serious adverse effects of the drug include: apnea, cardio-respiratory arrest (occurs usually in combination with a narcotic), oxygen desaturation, hypotension, respiratory depression, respiratory obstruction, bronchospasm and laryngospasm. Unopened vials are stored at room temperature (between 68-77 degrees Fahrenheit or 20-25 degrees Celsius) and are stable up to 36 days. Protect from light. ${ }^{32}$ Over sedation can be reversed with the administration of $0.2 \mathrm{mg}$ IV flumazenil (Romazicon, Anexate).

Diazepam (Valium) works similarly as midazolam. It is a member of the following classes: antianxiety, anticonvulsant, benzodiazepine, and long-acting skeletal muscle relaxant. It potentiates the actions of $\gamma$-aminobutyric acid (GABA), especially in the limbic system and reticular formation; enhances presympathetic inhibition, and inhibits spinal polysynaptic afferent paths. It is used for anxiety, acute alcohol withdrawal, as an adjunct in seizure disorders; as a relaxant both preoperatively and general skeletal muscle relaxation (adjunct for skeletal muscle spasm). Given rectally, it is used in acute repetitive (refractory) seizures. Other uses of diazepam are: for agitation, benzodiazepine withdrawal, chloroquine overdose, insomnia, and as seizure prophylaxis. ${ }^{32}$ For sedation during endoscopic procedures, a dose of $10 \mathrm{mg}$ or less is given intravenously prior to the procedure for a maximum dose of $20 \mathrm{mg}$. Patients 60 years and older, chronically ill, debilitated or with hepatic insufficiency will require less. There are no specific dose adjustments in patients with renal insufficiency. Due to the irritating nature of the drug, administration must be done slowly, no faster than $5 \mathrm{mg} / \mathrm{min}$., and if given through IV infusion tubing, give as close to the IV insertion site as possible. Do not inject into small veins (irritating and may cause phlebitis) or through intravenous sets made of polyvinyl chloride (PVC). Diazepam binds to polyvinyl chloride. ${ }^{32}$

Contraindications to its administration are severe hepatic insufficiency, hypersensitivity to diazepam, myasthenia gravis, acute narrow-angle glaucoma, severe respiratory insufficiency, sleep apnea, and children less than 6 months of age. Diazepam is $99 \%$ protein bound (and significantly greater in males than in females), metabolized extensively in the liver and excreted in the urine. It is excreted in breast milk, crosses the placenta and bloodbrain barriers. It has a half-life of 30-60 hours. Given intravenously, it has an immediate effect and has a duration of about 15 minutes to an hour. Side effects are similar to midazolam and include: dizziness, drowsiness, confusion, headache, anxiety, tremors, stimulation, fatigue, depression, insomnia, hallucinations, ataxia, hypotension, ECG changes and tachycardia. Some, especially for prolonged users, experience blurred vision, tinnitus, mydriasis, nystagmus, constipation, dry mouth, nausea, vomiting, diarrhea, anorexia, neutropenia, rash, dermatitis, and itching. Injectable diazepam can be stored at room temperature and has been found to maintain stability up to 5 months; otherwise, store at temperatures 25 degree Celsius (77 F) or lower to prevent deterioration.

Both diazepam and midazolam are similar in producing effective sedation prior to short surgical as well as endoscopic procedures. However, midazolam produced a greater degree of amnesia, lesser pain on injection, and lesser phlebitis at injection site than diazepam. It also produced a greater respiratory depression than diazepam during the first 45 minutes of administration, though the latter sustained the effects longer than midazolam after an hour of administration. Midazolam was also more acceptable to patients than those given diazepam. Hence, midazolam is now the agent of choice when amnesia and adequate sedation is required. One disadvantage, though, noted with the administration of 
benzodiazepines is that since they are fat-soluble (particularly diazepam), repeated dose results in accumulation of the drug in the adipose tissues which is subsequently released into the bloodstream resulting in prolonged effects. Hence, the most common reasons for missing work were feeling weak and drowsy or having abdominal cramping and bloating. ${ }^{22}$ Over sedation can be reversed with the administration of $0.2 \mathrm{mg}$ IV flumazenil (Romazicon, Anexate).

\subsection{Opiates}

The sedative and amnesic effects of benzodiazepines often times do not provide adequate comfort for patients undergoing endoscopic procedures, especially if the procedure lasts longer than half-an-hour. For this reason, opiates are often added to achieve optimum sedation and analgesia. Very few studies have been done to evaluate the efficacy of adding an opiate prior to colonoscopy and authors have casted doubt on its benefit. ${ }^{8}{ }^{10},{ }^{17}$ The two commonly used opiates are meperidine (Demerol) and fentanyl.

Meperidine (Demerol) is an analgesic, anesthetic adjunct, and is an opioid. It is indicated as an anesthetic adjunct, for obstetrical pain, and as premedication for a procedure. It depresses pain impulses at the spinal cord level by interacting with opioid receptors. For endoscopic procedures, meperidine is dosed as follows: initial bolus of $25 \mathrm{mg}$ (given slowly) and subsequent incremental doses of $25 \mathrm{mg}$ every 2-3 minutes until the desired effect is achieved. Colonoscopy is usually started two to three minutes after the initial bolus of meperidine and midazolam and titration delivery was given every three minutes thereafter with meperidine $25 \mathrm{mg}$ and midazolam $1 \mathrm{mg}$ until the desired sedation effect was achieved, i.e. ptosis, slurred speech, and sleep. See Table 2 for dosing guidelines.

Meperidine is readily absorbed and crosses the blood-brain and placental barriers. It is 65$80 \%$ protein bound, metabolized in the liver and excreted in the kidneys. It has an elimination half-life of 3.2-3.7 hours. It is contraindicated in individuals with hypersensitivity to meperidine and those who are taking MAOI (monoamine oxidase inhibitor) drugs. Use with caution in individuals with low blood volume, receiving concomitant CNS depressants (reduce dosage), head injury, impaired respiratory function, acute abdominal conditions, Addison's disease (reduce dosage), elderly, debilitated, hypothyroidism, prostatic hypertrophy and urethral strictures, seizures (may induce more), severe hepatic and renal impairment, cardiac dysrhythmias such as SVTs and A-flutter. Side effects include: CNS: drowsiness, dizziness, confusion, headache, sedation, euphoria, increased intracranial pressure, seizures and serotonin syndrome; CV: palpitations, bradycardia, hypotension and orthostatic hypotension, tachycardia; EENT: tinnitus, blurred vision, miosis, diplopia, depressed corneal reflex; GI: nausea, vomiting, anorexia, constipation, cramps, biliary spasm, and paralytic ileus; GU: urinary retention, dysuria; Integ: rash, urticarial, bruising, flushing, diaphoresis, xerostomia and pruritus. Adverse effects include respiratory depression, cardiac arrest and anaphylaxis. Use judiciously when used in conjunction with benzodiazepines because of its added CNS and respiratory depressant effects. ${ }^{32}$

The other opioid of choice is fentanyl which shares the same classification as meperidine: analgesic, anesthetic adjunct, and opioid. It acts by inhibiting the ascending pain pathways in the CNS (central nervous system), increases pain threshold, and alters pain perception by binding to opioid receptors. It is used to control moderate to severe pain, as an adjunct to general and regional anesthesia, and premedication for procedures requiring conscious 
sedation, such as colonoscopy. Compared to meperidine, fentanyl has a more rapid onset of action and clearance. It also has a lesser incidence of nausea than meperidine.

For procedural sedation, the suggested doses are 0.5 to $1.5 \mathrm{mcg} / \mathrm{kg}$ intravenously and repeated every 1 to 3 minutes until the desired sedative effects is achieved. Administer slowly to prevent rigidity. It is metabolized by the liver, excreted in the kidneys and breast milk and crosses the placenta. Given intravenously, its onset is immediate, within a minute, peaking in 3-5 minutes for $1 / 2-1$ hour. It has a half-life of $1 \frac{1 / 2-6}{2}$ hours and is $80 \%$ bound to plasma proteins. Side effects are similar to meperidine and include: dizziness, delirium, bradycardia, hypo/hypertension, blurred vision, miosis, nausea, vomiting, constipation, urinary retention, rash, diaphoresis, muscle rigidity, cardio-respiratory depression and/or arrest, and laryngospasm. It is contraindicated in individuals with myasthenia gravis and those with hypersensitivity to opiates, bronchial asthma, paralytic ileus, situations of significant respiratory distress. ${ }^{32}$

Opioids and benzodiazepines combined work synergistically. Antagonists of these medications are naloxone (Narcan) for opiates (typical dose is $40-400 \mathrm{mcg}$ IV) and flumazenil (Romazicon) for benzodiazepines (typical dose is $40-400 \mathrm{mcg}$ IV). These drugs should be readily available in every GI suite to rescue a patient who has been given too much sedative and whose cardiorespiratory status is compromised.

\subsection{General anesthetic}

The only drug used in colonoscopy in this category is propofol (Diprivan). It produces a dose-dependent CNS depression by activating the GABA receptors. Its principal uses are for the induction and maintenance of anesthesia and sedation in mechanically ventilated patients. It also potentiates the effects on the central nervous system of analgesics and sedatives such as benzodiazepines and barbiturates. It has a rapid onset of sedation, but also marked cardio-respiratory depressant properties. These side effects usually rapidly diminish or reverse with reduction of dose or stopping of administration or infusion of propofol. There has been an increase in its use in endoscopic procedures because of its rapid onset and faster recovery to alertness properties with minimal residual sedative effects, which makes it an attractive alternative to the longer half-life benzodiazepines. ${ }^{22,11}$ Do not use within 10 days of intake of monoamine oxidase inhibitors (MAOI). This drug potentiates CNS depression in individuals taking antipsychotic drugs, opioids, skeletal muscle relaxants, St. John's wort and alcohol. ${ }^{32}$

Propofol may be used alone or in combination with other agents such an opioid or benzodiazepine. When used alone, higher doses are often required to achieve the desired sedation level which increases the risks of dose-related side effects such as hypotension, respiratory depression, and bradycardia. In combination with other agents, the clinician can adjust the dosages which usually results in administration of smaller dosages of each of the agents to achieve moderate sedation level. If necessary, the effects of the opioid and benzodiazepine can be reversed with naloxone and flumazenil. Propofol does not have an antidote or reversal agent as its half-life is short and the effects wear off as soon as the infusion of the drug is stopped. ${ }^{9}$

Though theoretically, propofol in combination with an opioid or benzodiazepine will decrease the rapid recovery benefit seen with administration of propofol alone, a randomized control trial proved otherwise. The results showed a shorter recovery time with the combination regimen than the propofol alone. ${ }^{35}$ 
The drug is highly lipophilic. There are two preparations that exist on the market. One is prepared as an oil/water emulsion (Diprivan) consisting of $1 \%$ propofol, $10 \%$ soybean oil, $2.25 \%$ glycerol, $1.2 \%$ egg lecithin and the antimicrobial agent, EDTA. This preparation is contraindicated in individuals with propofol, soy or egg hypersensitivities or allergies. The other generic preparation has bisulfites (sodium metabisulfite) as the antimicrobial agent and is therefore, contraindicated in individuals with hypersensitivity or allergy to bisulfites. ${ }^{4}, 32$

Propofol is notorious for being painful at the injection site, often described as a burning sensation. Several approaches have been employed to minimize this discomfort. One is the administration of $1-2 \mathrm{ml}$ of $1 \%$ lidocaine prior to injecting propofol or mixing lidocaine and propofol in the same syringe. Another approach is diluting propofol in a $5 \%$ glucose solution. A study found that there was less pain at the injection site in individuals given the generic propofol (bisulfite-containing propofol) than those given Diprivan. ${ }^{32}$

Propofol is a category B drug and should be used with caution in lactating mothers as it is excreted in breast milk. It is $98 \%$ plasma-protein bound, is metabolized primarily in the liver, and excreted in the kidneys. Usual time from injection to onset of sedation is anywhere from 13-30 seconds and the duration is about 4-8 minutes. ${ }^{4}$ Table 4 shows a summary of commonly used drugs in colonoscopy.

\begin{tabular}{|c|c|c|c|c|c|c|}
\hline $\begin{array}{c}\text { Drug } \\
\text { (Trade } \\
\text { Name) }\end{array}$ & Class & Effects & $\begin{array}{c}\text { Dosing } \\
\text { Guidelines }\end{array}$ & $\begin{array}{c}\text { Onset/ } \\
\text { Peak }\end{array}$ & $\begin{array}{c}\text { Duration/ } \\
\text { Half-life }\end{array}$ & Adverse Effects \\
\hline $\begin{array}{c}\text { Meperidine } \\
\text { (Demerol) }\end{array}$ & $\begin{array}{l}\text { Opioid } \\
\text { Anesthetic } \\
\text { adjunct } \\
\text { Analgesic }\end{array}$ & $\begin{array}{c}\text { Sedation } \\
\text { Anal- } \\
\text { gesia }\end{array}$ & $\begin{array}{c}\text { Bolus } 25 \mathrm{mg} \\
\text { slowly and } \\
\text { incremental } \\
\text { doses of } 25 \mathrm{mg} \\
\text { every 2-3 min. } \\
\text { titrated to } \\
\text { effect }\end{array}$ & $\begin{array}{l}5 \text { min. } \\
\text { Peaks in } \\
10 \text { min. }\end{array}$ & $\begin{array}{c}\text { 2-4 hrs. / } \\
\text { Half-life } \\
\text { of 3-5 hrs. }\end{array}$ & $\begin{array}{c}\text { Respiratory } \\
\text { depression, } \\
\text { seizures, } \\
\text { hypotension, } \\
\text { nausea, vomiting } \\
\text { tachycardia, and } \\
\text { hypoventilation, } \\
\text { SVTs } \\
\text { confusion, } \\
\text { euphoria }\end{array}$ \\
\hline $\begin{array}{c}\text { Midazolam } \\
\text { (Versed) }\end{array}$ & $\begin{array}{l}\text { Benzodia- } \\
\text { zepine } \\
\text { Anesthetic } \\
\text { adjunct } \\
\text { Short or } \\
\text { intermediate } \\
\text { hypnotic }\end{array}$ & $\begin{array}{c}\text { Sedation } \\
\text { Amnesia } \\
\text { Anxi- } \\
\text { olytic }\end{array}$ & $\begin{array}{c}\text { Bolus } 0.5-2 \mathrm{mg} \\
\text { with } \\
\text { incremental } \\
\text { doses of } 2-5 \mathrm{mg} \\
\text { every } 2-3 \mathrm{~min} \\
\text { titrated to } \\
\text { effect }\end{array}$ & $\begin{array}{c}1-5 \\
\text { min./ } \\
\text { Peaks in } \\
3-5 \text { min. }\end{array}$ & $\begin{array}{c}1-3 \text { hrs. / } \\
\text { Half-life } \\
\text { of } 1.8-6.4 \\
\text { hrs. }\end{array}$ & $\begin{array}{c}\text { Apnea, } \\
\text { hypotension, } \\
\text { hypoventilation, } \\
\text { cardiac } \\
\text { arrhythmias } \\
\text { (PVCs), } \\
\text { bronchospasm, } \\
\text { anxiety, } \\
\text { laryngospasm, } \\
\text { dyspnea, } \\
\text { respiratory } \\
\text { depression, } \\
\text { headache, } \\
\text { agitation }\end{array}$ \\
\hline
\end{tabular}




\begin{tabular}{|c|c|c|c|c|c|c|}
\hline $\begin{array}{c}\text { Drug } \\
\text { (Trade } \\
\text { Name) }\end{array}$ & Class & Effects & $\begin{array}{c}\text { Dosing } \\
\text { Guidelines }\end{array}$ & $\begin{array}{l}\text { Onset/ } \\
\text { Peak }\end{array}$ & $\begin{array}{l}\text { Duration/ } \\
\text { Half-life }\end{array}$ & Adverse Effects \\
\hline $\begin{array}{c}\text { Diazepam } \\
\text { (Valium) }\end{array}$ & $\begin{array}{c}\text { Benzo- } \\
\text { diazepine } \\
\text { Antianxiety } \\
\text { Anticon- } \\
\text { vulsant } \\
\text { Long-acting } \\
\text { skeletal } \\
\text { muscle } \\
\text { relaxant }\end{array}$ & $\begin{array}{l}\text { Amnesia } \\
\text { Anxi- } \\
\text { olytic } \\
\text { Sedation }\end{array}$ & $\begin{array}{c}\text { Bolus slowly } \\
2.5-10 \mathrm{mg} \text { IV } \\
\text { maximum of } \\
\text { 20mg (Do not } \\
\text { mix or dilute } \\
\begin{array}{c}\text { w/other drugs } \\
\text { or solutions in } \\
\text { syringe)* }\end{array}\end{array}$ & $\begin{array}{c}1-5 \\
\text { min./ } \\
\text { Peaks in } \\
8 \text { min. }\end{array}$ & $\begin{array}{c}15 \text { min. to } \\
1 \text { hr./ } \\
\text { Half-life } \\
30-60 \text { hrs } \\
\text { and } \\
\text { increases } \\
\text { with age } \\
\text { and } \\
\text { obesity } \\
\text { (79-95 } \\
\text { hrs.) }\end{array}$ & \begin{tabular}{|c} 
Cardiac \\
dysrhythmia, \\
tachycardia, \\
vasculitis, \\
hypotension, \\
respiratory \\
depression, \\
confusion, \\
thrombophlebitis, \\
ataxia, \\
hallucination, \\
tremors, \\
confusion, fatigue, \\
dizziness
\end{tabular} \\
\hline \begin{tabular}{|c|} 
Fentanyl \\
(Sublimaze, \\
Fentanyl)
\end{tabular} & $\begin{array}{l}\text { Opioid } \\
\text { Anesthetic } \\
\text { adjunct } \\
\text { Analgesic }\end{array}$ & $\begin{array}{l}\text { Analgesia } \\
\text { Sedation }\end{array}$ & \begin{tabular}{|c|} 
Bolus with $50-$ \\
$100 \mathrm{mcg}$. Or \\
$0.5-1.5 \mathrm{mcg} / \mathrm{kg}$ \\
per dose. \\
Additional \\
doses at $0.5-$ \\
$1 \mathrm{mcg} / \mathrm{kg}$ per \\
dose titrated \\
to effect**
\end{tabular} & $\begin{array}{c}<1 \mathrm{~min} / \\
\text { Peaks in } \\
3-5 \mathrm{~min} . \\
\text { for } 1 / 2- \\
1 \mathrm{hr}\end{array}$ & $\begin{array}{c}30- \\
60 \mathrm{~min} . / \\
1.5-6 \\
\text { hours }\end{array}$ & $\begin{array}{c}\text { Respiratory } \\
\text { depression, } \\
\text { hypoventilation, } \\
\text { decrease in tidal } \\
\text { volume, muscle } \\
\text { rigidity, delirium, } \\
\text { rash, blurred } \\
\text { vision, miosis, } \\
\text { bradycardia, } \\
\text { diaphoresis, } \\
\text { laryngospasm }\end{array}$ \\
\hline \begin{tabular}{|l|} 
Propofol \\
(Diprivan, \\
Fresenius, \\
Propoven)
\end{tabular} & $\begin{array}{l}\text { Ultra short- } \\
\text { acting } \\
\text { hypnotic } \\
\text { and sedative }\end{array}$ & $\begin{array}{l}\text { Amnesia } \\
\text { Hypnotic } \\
\text { Sedation }\end{array}$ & \begin{tabular}{|c|} 
Initial bolus of \\
$10-60 \mathrm{mg} ;$ \\
Additional \\
doses titrated \\
to level of \\
sedation \\
required every \\
$20-30$ seconds, \\
$0.1-0.2$ \\
$\mathrm{mg} / \mathrm{kg} / \mathrm{min}$
\end{tabular} & $\begin{array}{l}13-30 \\
\text { sec/ }\end{array}$ & $\begin{array}{l}4-8 \mathrm{~min} . / \\
1-8 \mathrm{~min} .\end{array}$ & $\begin{array}{c}\text { Respiratory } \\
\text { depression, } \\
\text { hypoventilation, } \\
\text { apnea seizures, } \\
\text { hypotension, } \\
\text { bradydysrhythmias, } \\
\text { hives, flushing, } \\
\text { phlebitis, burning } \\
\text { at injection site, } \\
\text { cough, hiccups, } \\
\text { asystole }\end{array}$ \\
\hline
\end{tabular}

*Drug is irritating to the vein, administer slowly

${ }^{* *}$ Administer slowly to prevent rigidity

Table 4. Commonly used sedation drugs in colonoscopy

\section{Adjuncts to sedation in colonoscopy}

There are several adjuncts to the combination of benzodiazepines and opiates. Among these are: Droperidol, promethazine, and diphenhydramine. These medications potentiate the 
action of the combined benzodiazepine and opiate and the result may be a deeper level of sedation. Adjuncts are employed when the first-line of sedatives fail to produce the desired level of sedation.

Diphenhydramine, better known as Benadryl, acts on the GI tract, blood vessels, and respiratory system by competing with histamine for $\mathrm{H}-1$ receptor sites, thereby decreasing histamine's actions. It is usually used for allergy symptoms, rhinitis, motion sickness, nonproductive cough, antiparkinsonism, insomnia in children, infant colic, and for nighttime sedation. Effects are heightened in individuals taking MAOIs. Side effects include dizziness, drowsiness, anxiety, fatigue, euphoria, confusion, seizures, blurred vision, hypotension, blurred vision, urinary retention, hemolytic anemia, thrombocytopenia, agranulocytosis, chest tightness, wheezing, and anaphylaxis. Dose is $10-50 \mathrm{mg}$ IV. It is metabolized in the liver and excreted by the kidneys. It crosses the placenta and is excreted in breast milk. Its onset is immediate when given IV and the duration is 4-7 hours. ${ }^{32}$

Promethazine (Phenergan) acts the same way as diphenhydramine. Its uses are also similar to diphenhydramine. In addition, it is also used to counteract nausea and for preoperative and postoperative sedation. Side effects are the same as diphenhydramine with the addition of neuroleptic syndrome, neuritis and paresthesia, Dose is $12.5 \mathrm{mg}-50 \mathrm{mg}$ IV. Its onset is 3-5 minutes with duration of $4-12$ hours. It is metabolized in the liver and excreted in the kidneys and GI tract. ${ }^{32}$

Dropeidol (Inapsine) is a neuroleptic agent acting on the subcortical level producing sleep and tranquilization. It is used as premedication prior to surgery and induction and maintenance of general anesthesia. It is also used as an antiemetic postoperatively. It is also sometimes used for anxiety and for difficult to sedate individuals undergoing therapeutic endoscopy. However, this drug carries a black box warning from the Food and Drug Administration (FDA) warning users that it can prolong the QT interval and should be avoided in individuals with congestive heart failure (CHF), bradycardia, on diuretics, has cardiac hypertrophy, hypokalemia, hypomagnesemia, and are on drugs that normally prolong the QT interval. It is contraindicated in males whose QT intervals are $>440 \mathrm{msec}$. or for females whose QT intervals are $>450 \mathrm{msec}$. Individuals over the age of 65 , history of alcohol abuse, and use of benzodiazepines and opiates are also at risk. Side effects include seizures, neuroleptic malignant syndrome, torsade de pointes, prolonged QT interval, tachycardia, hypotension, hallucination, depression, extra pyramidal symptoms (EPS), laryngospasm, bronchospasm, chills, and sweating. Initial dose should start at $1.25 \mathrm{mg}$ IV. May give an additional $1.25 \mathrm{mg}$ IV dose to max of $2.5 \mathrm{mg}$. Its onset is $3-5 \mathrm{~min}$, peaking in $1 / 2$ an hour and duration of 3-6 hours. It is metabolized in the liver, excreted in the urine and crosses the placenta. It has a half-life of 2-3 hours. ${ }^{32}$

The long duration of actions of these adjuncts make it a less ideal drug for use in short procedures such as colonoscopy. Recovery will take a longer time and will not be cost effective for the GI unit.

\section{Conclusion}

Colonoscopy remains the gold standard in diagnosing gastrointestinal disorders. The test itself along with the preparation is anxiety provoking and frightening for most people. In many countries around the world, colonoscopy is commonly performed without sedation. The discomfort hampers completion of the test; hence, sedation is now the standard practice in endoscopic procedures, particularly colonoscopy. Benzodiazepines, opiates, and propofol 
are the commonly used sedating agents. Alone or in combination, many of these agents have been employed to maximize patient comfort and patient and physician satisfaction, but none have proved ideal. The widespread variation in sedation practices are also influenced by physician experience and expertise, financial and regulatory constraints, patient expectations and satisfaction, and lack of consensus on the ideal sedating agent for colonoscopy. More controlled clinical trials are needed to evaluate the safety and efficacy of the ideal sedating agent (s).

\section{Acknowledgement}

The author wishes to thank Kira Hulse, BS for her review and critique of the article and to Marian de la Cour, RN, BSN, MLS for all her efforts in obtaining most of the articles cited in this chapter and also for her review of this article.

\section{References}

[1] Aisenberg, J., Brill, J., Ladabaum, U. \& Cohen, L. (2005, May). Sedation for gastrointestinal endoscopy: New practices, new economics. American Journal of Gastroenterology, 100(5), 996-1000, ISSN 0002-9270.

[2] American Society of Anesthesiologists (2009, October). Standards and guidelines: Distinguishing monitored anesthesia care from moderate sedation/analgesia (Conscious sedation). Retrieved on March 10, 2011 from http://www.asahq.org/For-Healthcare-Professionals/Standards-Guidelines-andStatements.aspx

[3] American Society of Anesthesiology Task Force on Sedation and Analgesia by Nonanesthesiologists (2002, April). Anesthesiology, 96(4), 1004-1017. ISSN 0003-3022.

[4] American Society for Gastrointestinal Endoscopy (ASGE) (2008, November). Sedation and anesthesia in GI endoscopy. Gastrointestinal Endoscopy, 68(5), 815-826, ISSN 0016-5107.

[5] Arrowsmith, J., Gertsman, B., Fleischer, D. et al. (1991, July/August). Results from the American Society for Gastrointestinal endoscopy/US Food and Drug Administration collaborative study on complication rates and drug use during gastrointestinal endoscopy. Gastrointestinal Endoscopy, 37(4), 421-427, ISSN 0016-5107.

[6] Balsells, F., Wyllie, R., Kay, M. \& Steffen, R. (1997, May). Use of conscious sedation for lower and upper gastrointestinal endoscopic examinations in children, adolescents, and young adults: A twelve year review. Gastrointestinal

[7] Chung, F. (1995, November). Discharge criteria-a new trend. Canadian Journal of Anesthesia, 45(11), 1056-1058. Endoscopy, 45(5), 375-380, ISSN 0016-5107.

[8] Cohen, 1., Delegge,M., Aisenberg, J. et al. (2007). AGA Institute review of endoscopic sedation. Gastroenterology, 133, 675-701, ISSN 0016-5085.

[9] Cohen, L.,Wecsler, L., Gaetano, J. et. al. (2006, May). Endoscopic sedation in the United States: Results from a nationwide survey. American Journal of Gastroenterology, 101(5), 967-974, ISSN 0002-9270.

[10] Cohen, L., Hightower, C., Wood, D. et al. (2004, June). Moderate level sedation during colonoscopy: A prospective study using low-dose propofol, meperidine/fentanyl, and midazolam. Gastrointestinal Endoscopy, 59(7), 795-803, ISSN 0016-5107. 
[11] Deenadayalu, V., Eid, E., Goff, J. et al. (2008). Non-anesthesiologist administered propofol sedation for endoscopic procedures: A worldwide safety review (abstract). Gastrointestinal Endoscopy, 67, AB107.

[12] Froehlich, F., Harris, J., Wietlisbach, V., et al. (2006, May). Current sedation and monitoring practice for colonoscopy: An international observational study (EPAGE). Endoscopy, 38(5), 461-469. ISSN 0013-726x.

[13] Godwin, S., Caro, D., Wolf, S. et al. (2005, February). Clinical policy: Procedural sedation and analgesia in the emergency department. Annals of Emergency Medicine, 45(2), 177-196. ISSN 0196-0644.

[14] Gross, B., Bailey, P., Connis, R. et al (2002, April.) Practice guidelines for sedation and analgesia by non-anesthesiologists. Anesthesiology, 96(4), 1004-1017, ISSN 0003-3022.

[15] Heuss, L., Froehlich, F. \& Beglinger, C. (2005, May). Changing patterns of sedation and monitoring practice during endoscopy: Results of a nationwide survey in Switzerland. Endoscopy, 37(5), 161-166. ISSN 013-726x.

[16] Huang, R. \& Eisen, G. (2004, April). Efficacy, safety, and limitations in current practice of sedation and analgesia. Gastrointestinal Endoscopy Clinics of North America, 14(2), 269-288. ISSN 1052-5157.

[17] Jung, H., Bae, K., Yoon, S. et al. (2004, February). Comparison of midazolam versus midazolam/meperidine during colonoscopy in a prospective, randomized, double-blind study. Korean Journal of Gastroenterology, 43(2), 96-103, ISSN 1598-9992.

[18] Kissin, I., (2000, May). Depth of anesthesia and Bispectral Index Monitoring. Anesthesia $\mathcal{E}$ Analgesia, 90(5), 1114-1117, ISSN 003-2999.

[19] Kubilay, Ç., Yakut, M. \& Özden, A. (2009, December). Sedation with midazolam versus midazolam plus meperidine for routine colonoscopy: A prospective, randomized, controlled study. Turkish Journal of Gastroenterology, 20(4), 271-275, ISSN 1300-4948.

[20] Külling, D., Orlandi, M. \& Inauen, W. (2007, September). Propofol sedation during endoscopic procedures: How much staff and monitoring are necessary? Gastrointestinal Endoscopy, 66(3), 443-449, ISSN 0016-5107.

[21] Lee, H. \& Kim, J. H. (2009, August 14). Superiority of split dose midazolam as conscious sedation for outpatient colonoscopy. World Journal of Gastroenterology, 15(30), 37833787, ISSN 1007-9327.

[22] Lubarsky, D., Candiotti, K \& Harris, E. (2007, August). Understanding modes of moderate sedation during gastrointestinal procedures: A current review of the literature. Journal of Clinical Anesthesia, 19(5), 397-404. ISSN 0952-8180.

[23] McQuaid, K. \& Laine, L. (2008, May). A systematic review and meta-analysis of randomized, controlled trials of moderate sedation for routine endoscopic procedures. Gastrointestinal Endoscopy, 67(6), 910-922, ISSN 0016-5107. Mosby's Nursing Drug Reference

[24] Ong, W., Santosh, D., Lakhtakia, S. \& Reddy. (2007, September). A randomized, controlled trial on use of propofol alone versus propofolwith midazolam, ketamine, and pentazocine "sedato-analgesic cocktail" for sedation during ERCP. Endoscopy, 39(9),807-812. ISSN 0013-726x.

[25] Padmanabhan, U., Leslie, K., SingYi Eer, A. et al. (2009, November). Early cognitive impairment after sedation for colonoscopy: The effect of adding midazolam and/or fentanyl to propofol. Anesthesia $\mathcal{E}$ Analgesia, 109(5), 1448-1455 ISSN 0003-2999.

[26] Padmanabhan, U. \& Leslie, K. (2008, May)). Australian anesthetists' practice of sedation for gastrointestinal endoscopy in adult patients. Anaesthesia and Intensive Care, 36(3), 436-441. 
[27] Qadeer, M.,Vargo, J., Khandala, F. et al (2005, November). Propofol versus traditional sedative agents for gastrointestinal endoscopy: Ameta-analysis. Clinical Gastroenterology and Hepatology, 3(11), 1049-1056. ISSN1542-3565.

[28] Rex, D. \& Khalfan, H. (2005, October). Sedation and the technical performance of colonoscopy. Gastrointestinal Endoscopy Clinics of North America, 15(4), 661-672. ISSN $1052-5157$.

[29] Rex, D., Overley, C., Kinser, K. et al. (2002, May). Safety of propofol administration by registered nurses with gastroenterologist supervision in 2000 endoscopic cases. American Journal of Gastroenterology, 97(5), 1159-1163, ISSN 0002-9270.

[30] Seifert, H., Schmitt, T., Gültekin, T., Caspary, W. \& Wehrmann, T. (2000, September). Sedation with propofol plus midazolam versus propofol alone for interventional endoscopic procedures: A prospective, randomized study. Alimentary Pharmacology E Therapeutics, 14(9), 1207-1214, ISSN 1365-2036.

[31] The Merriam-Webster Dictionary (1997). Springfield, MA USA, ISBN 0-87779-911-3.

[32] Tohda, G., Higashi, S., Wakahara, S. et al. (2006,April). Propofol sedation during endoscopic procedures: Safe and effective administration by registered nurses supervised by endoscopists. Endoscopy, 38(4), 360-367. ISSN 0013-726x.

[33] Tohda, G., Higashi, S., Sakumoto, H., et al. (2006, July). Efficacy and safety of nurseadministered propofol sedation during emergency upper endoscopy for gastrointestinal bleeding: A prospective study. Endoscopy, 38(7), 684-689, ISSN 0013726x.

[34] VanNatta, M. \& Rex, D. (2006). Propofol alone titrated to deep sedation versus propofol in combination with opioids and/or benzodiazepines and titrated to moderate sedation for colonoscopy. American Journal of Gastroenterology, 101, 2209-2217, ISSN 0002-9270.

[35] Vargo, J., Bramley, T., Meyer, K. et al. (2007, July). Practice efficiency and economics: The case for rapid recovery sedation agents for colonoscopy in a screening population. Journal of Clinical Gastroenterology, 41(6), 591-598. ISSN 0192-0790.

[36] Vargo, J., Zuccaro, G.,Dumot, J., et al. (2002, July). Gastroenterologist-administered propofol versus meperidine and midazolam for advanced upper endoscopy: A prospective, randomized trial. Gastroenterology, 123(1), 8-16, ISSN 0016-5085.

[37] Waring, J., Baron, T., Hirota, W. et al. (2003, September). Guidelines for conscious sedation and monitoring during gastrointestinal endoscopy. Gastrointestinal Endoscopy, 58(3), 317-322, ISSN 0016-5107.

[38] Wehrmann, T. \& Riphaus, A. (2009, January). Sedation, surveillance, and preparation. Endoscopy, 41(1), 86-90. ISSN 0013-726x.

[39] White, P., Fanzca, S. \& Dajun, S. (1999). New criteria for fast-tracking after out-patient anesthesia: A comparison with the Modified Aldrete's Scoring System, Anesthesia $\mathcal{E}$ Analgesia, 88, 1069-1072, ISSN 0003-2999.

[40] Shao, X., Hong, L., White, P., et al (2000, May). Bisulfite-containing propofol: Is it a costeffective alternative to Diprivan for induction of anesthesia? Anesthesia $\mathcal{E}$ Analgesia, 91, 871-875, ISSN 0003-2999.

[41] Zavoral, M., Suchanek, S., Zavada, F. et al. (2009, December 21). Colorectal cancer screening in Europe. World Journal of Gastroenterology, 15(47), 5907-5915, ISSN 10079327. 
ENDOSCOPIC PROCEDURES

IN COLON AND RECTUM

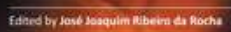

\section{Endoscopic Procedures in Colon and Rectum}

Edited by Prof. Jose Ribeiro Da Rocha
ISBN 978-953-307-677-5

Hard cover, 156 pages

Publisher InTech

Published online 07, November, 2011

Published in print edition November, 2011

Endoscopic procedures in colon and rectum presents nine chapters which start with introductory ones like screening by colonoscopy as the preparation and monitoring for this exam. In addition to these approaches the book aims in the last four chapters to explain endoscopic diagnostic and therapeutic aspects in the colon and rectum. The description of each text is very comprehensive, instructive and easy to understand and presents the most current practices on the topics described. This book is recommended for general and colorectal surgeons as it presents guidelines for diagnosis and treatment which are very well established.

\section{How to reference}

In order to correctly reference this scholarly work, feel free to copy and paste the following:

Rosalinda S. Hulse (2011). Monitoring During Colonoscopy, Endoscopic Procedures in Colon and Rectum, Prof. Jose Ribeiro Da Rocha (Ed.), ISBN: 978-953-307-677-5, InTech, Available from:

http://www.intechopen.com/books/endoscopic-procedures-in-colon-and-rectum/monitoring-during-colonoscopy

\section{INTECH}

open science | open minds

\section{InTech Europe}

University Campus STeP Ri

Slavka Krautzeka 83/A

51000 Rijeka, Croatia

Phone: +385 (51) 770447

Fax: +385 (51) 686166

www.intechopen.com

\section{InTech China}

Unit 405, Office Block, Hotel Equatorial Shanghai

No.65, Yan An Road (West), Shanghai, 200040, China 中国上海市延安西路65号上海国际贵都大饭店办公楼 405 单元 Phone: $+86-21-62489820$

Fax: +86-21-62489821 
(C) 2011 The Author(s). Licensee IntechOpen. This is an open access article distributed under the terms of the Creative Commons Attribution 3.0 License, which permits unrestricted use, distribution, and reproduction in any medium, provided the original work is properly cited. 